\title{
PROVISION OF EMERGENCY MEDICAL SERVICES IN RURAL AND URBAN SAUDI ARABIA: AN OVERVIEW OF PERSONNEL EXPERIENCES
}

\author{
Ahmed Alanazy, John Fraser, Stuart Wark \\ School of Rural Medicine, University of New England, NSW A ustralia \\ Correspondence:swark5@une.edu.au
}

\begin{abstract}
OBJECTIVE:

Pre-hospital emergency medical services (EMS) are a vital component of health management, however there are disparities in the provision of EMS between rural and urban locations. While rural people experience lower levels of prehospital care, there has been little examination of the reasons underpinning these differences through discussion with the providers of EMS, and particularly in countries other than the USA, UK and Australia. The purpose of this paper is to provide an overview of the lived experience of EMS personnel in Saudi Arabia regarding the key issues they face in their work practice.
\end{abstract}

\section{DESIGN:}

This research focussed on frontline workers and middle-level station managers within the Saudi Arabian EMS system and adopted a hermeneutic phenomenology design to better understand the factors contributing to observed disparities between rural and urban areas in Riyadh region in Saudi Arabia. A semi-structured interview approach was used to collect data reflecting realistic experiences of EMS personnel in both urban and rural locations.

RESULTS:

20 interviews (10 each with rural and urban personnel) were undertaken. Data analyses identified three primary thematic categories impacting EMS delivery: EMS personnel factors; Patient factors; and Organisational factors. Underpinning each category were sub-themes, including working conditions, stress, education and training, and resources, amongst others.

\section{CONCLUSIONS:}

The quality and efficiency of EMS services, in both rural and urban areas, was affected by a number of over-arching organizational factors. Implementing major policy shifts, such as recruitment of female EMS professionals, will be critical in addressing these challenges, but is acknowledged that this will take time. Quicker changes, such as improving the advanced training options for rural EMS staff, may help to remediate some of the issues. Public awareness campaigns may also be effective in addressing the identified misconceptions about the role of EMS in Saudi Arabia.

\section{KEYWORDS}

Emergency Medical Services; Health services management; Intensive and critical care; Rural; Urban 


\section{INTRODUCTION}

Pre-hospital emergency medical services (EMS) are an integral component of the overall health management system. They deliver a vital stage in treating patients, with this provision of care resulting in reduced mortality and limiting ongoing health co-morbidities. [1] However, it is known that there is a disparity in the provision of EMS, with rural people in some countries experiencing lower levels of pre-hospital health care when compared to their metropolitan peers. [2] This is particularly problematic when recognizing that EMS may be the only guaranteed health support for individuals who live in remote rural areas. [3] It has been identified that EMS in rural locations have worse outcomes relative to metropolitan sites in some key areas, such as the response and duration time, patient outcomes and operational factors. [4-7] As an example, cardiac arrest patients in rural areas are reported as having lower survival rates prior to hospital admission compared to urban patients. [8] Rural areas have reduced access to specialist EMS service options [4] which are in turn likely to have additional access issues, such as considerable geographic distances and poor road conditions, not similarly experienced in urban areas. [4, 9] However, most of this research has been undertaken in a small number of countries, such as the USA and Australia, [4] with little previously known about urban and rural differences in countries including the Kingdom of Saudi Arabia. Equally, while urban / rural disparities in EMS performance have been identified, there has been little examination of the perceived reasons underpinning these differences through discussion with the actual providers of EMS care.

This paper is part of a larger study looking at the provision of EMS in both rural and urban areas of Saudi Arabia. It specifically builds on the knowledge gained through earlier quantitative work that examined EMS service provision in rural and urban locations in Saudi Arabia [10-12]. This paper provides an overview of the lived experience and direct insights of EMS personnel in Saudi Arabia regarding the key issues that staff face in their day-to-day work practice and identifies factors that may lead to differences between rural and urban areas. The purpose of this paper is to overview the major findings and conclusions, with further papers which provide more detailed analyses under current development.

\section{METHODOLOGY}

The project was formally approved by the University of New England's Human Research Ethics Committee, the Saudi Arabia Ministry of Health Ethical Committee, The King Abdelaziz Medical Cities Ethical Committee, and the Saudi Red Crescent Authority.

\section{Study Design}

This researchrecognizes frontline workers (paramedics and emergency medicine technicians) and middle-level station managers within the Saudi Arabian EMS system as being well positioned to provide information regarding the day-to-day challenges of delivering EMS across rural and urban locations. From this starting point, the project adopted a hermeneutic phenomenology design to examine and better understand the factors that contributes to the observed disparities in EMS between rural and urban areas in Saudi Arabia [10-12]. The selection of hermeneutic phenomenology was informed by the need to collect data that both explains and demonstrates the particular concerns and challenges encountered by different stakeholders responsible for the provision of EMS care. One of the benefits of adopting a hermeneutic phenomenology research design involves understanding the context of organizations providing EMS, and through this, allowing for a reflective assessment of service delivery experiences. $[13,14]$ With these considerations, a semistructured interview approach was deemed most appropriate for ensuring collection of data that reflects the realistic experiences of EMS personnel in both urban and rural locations.

\section{Materials}

Using the findings from quantitative data collected from the earlier stages of the project [10-12], a semi-structured interview guide was established by the research team prior to this stage of the research commencing. It should be clearly noted that the purpose of these interviews was specifically to identify areas of improvement for EMS in rural and urban Saudi Arabia, and therefore the resulting data from this stage does not reflect overall satisfaction with the EMS work environment.

Two participants were involved in a pilot of the interview guide, with a goal of ensuring the questions were relevant, understandable, and addressed the specific issues of interest $[15,16]$. The data from these interviews were not 
specifically analyzed or included in the final dataset. Instead, the research team discussed the questions with the pilot participants and evaluated the effectiveness of each question through open discussion. Minor changes to improve clarity of a few questions were identified through this piloting of the interview guide, and these amendments were incorporated into the final version.

\section{Research study Environment}

The study was done within Riyadh region of Saudi Arabia and involved EMS personnel participants from both rural and urban areas. The population of Riyadh region is approximately 8 million people, including the capital city of Saudi Arabia, Riyadh city. Riyadh region forms one of the thirteen administrative regions within the Kingdom, incorporating a diverse range of both urban and rural settings, and is geographically located approximately in the centre of Saudi Arabia.

\section{Participants}

Participants for the interviews were sourced from Saudi Red Crescent, which is the leading provider of EMS services in Saudi Arabia. [5] All potential participants had been involved in the previous stages of the study and at that time expressed their willingness to undertake a follow-up personal interview. Eligibility criteria for inclusion in this interview stage included that the participant must have current employment with Saudi Red Crescent in defined roles as emergency medicine technician (EMT), paramedic, or EMS facility manager. To ensure a suitable level of practical knowledge, participants were also required to have a minimum of five years of experience with the EMS.

An expression of interest was sent to all individuals that had agreed to a follow-up interview and met the eligibility requirements for inclusion in the study. Participants were arranged based on first responders and continued until data saturation was reached. A pre-determined figure of 8-12 interviews was proposed for rural EMS personnel in conjunction with another 8-12 interviews for urban EMS personnel so as to purposivelysample staff in both types of location.

\section{Data Collection Procedure}

The interviews were conducted between October 2019 and July 2020. Data collection occurred in two phases; the first phase involved physical face-to-face interview within Riyadh region, while the Zoom platform (an online technology) was employed in a number of follow-up interview sessions. All interviews were undertaken in Arabic and recorded (with prior consent). These interviews were then transcribed verbatim and translated into English. Most participants were multi-lingual in both English and Arabian, and they were provided with both the transcript and translation to confirm the content. A small number of participants were not English speakers and therefore only their Arabic transcripts was shared. Once participants indicated their satisfaction with the transcription, the interviews underwent a process of certified translation in order to validate the contents. Following initial analyses by the research team (see below), a second interview phase was undertaken on Zoom to clarify any issues or statements that were considered unclear.

\section{Analysis}

The analyses of interview data involved the use of thematic analysis methodology [17] and was undertaken in accordance with the framework of Braun \& Clarke. [18] This process involved assigning a unique identifier for every interviewee, years of experience in the EMS, and individual location in either a rural or urban region. The first stage of analysis involved each member of research team independently reading the transcripts to initially establish preliminary key themes. This was followed by a series of group meetings to create an agreed coding structure through an iterative process, and which was informed by these preliminary thematic areas. Discussions on the observed themes resulted in determination of the agreed coding structure in this stage through group consensus. This process was followed by the coding of each of the English translations of the transcripts in line with this agreed coding structure. This process also identified specific thematic areas that were considered worthy of clarification or further exploration, and this was undertaken through follow-up interviews using the 'Zoom' on-line application.

\section{RESULTS}

\section{Participant Demographics}

20 interviews were undertaken; 10 with rural EMS staff and 10 with urban EMS staff. The known demographics of EMS providers in Saudi Arabia meant that all the participants were male. Rural participants had a mean age of 35.25 , with 11.5 years of experience, while the urban participants had a mean age of 32.5 years with 9.9 years of experience. With respect to their job roles, there were 10 EMTs (6 rural and 4 urban), 3 paramedics (0 rural and 3 urban) and 7 
station managers (4 rural and 3 urban). All station managers had previously worked in EMS delivery.

\section{Thematic Categories and Sub-Themes}

The purpose of the interviews was to identify possible barriers and facilitators of EMS delivery, either specific to a geographic location or generally for the entire system. The following data should not be read as reflecting participant' general satisfaction or dissatisfaction with the overall performance of the Saudi Red Crescent.

The analysis of the interview transcripts identified three primary thematic categories that impacted on EMS delivery in Saudi Arabia. These three categories were EMS personnel factors; patient factors; and organisational factors. Underpinning each of these three categories were a number of sub-themes including issues such as working conditions, stress, education and training, and resources, amongst others. The following results are presented in terms of each of the three over-arching categories, with separate tables outlining the sub-themes.

\section{EMS Personnel Factors}

The participants identified a number of issues relating to their role as an EMS staff member, and how job satisfaction, support and career progression can all play a key role in the successful delivery of EMS, or, equally, how they can impede it. The participants noted a number of positive areas of work, including the personal reward they feel in providing care, along with the financial security the job brings. They also specifically commented on the positive working environment, and the support they receive from their colleagues. However, there were also a number of negative issues identified, including a lack of training and ongoing education opportunities in rural areas, with the absence of female EMS staff across both rural and urban areas recognised as a significant problem when attempting to support female members of the public.

\section{TABLE 1: EMS PERSONNEL FACTORS}

\begin{tabular}{|c|c|}
\hline SUB-THEME & EXAMPLAR QUOTES \\
\hline Caring role & $\begin{array}{l}\text { Rural EMT } \\
\text { What I love most about my job is that I will get the reward from God } \\
\text { for saving lives }\end{array}$ \\
\hline Work conditions & $\begin{array}{l}\text { Rural EMT } \\
\text { I earn a good salary from it which helps me sustain my family. } \\
\text { Urban manager } \\
\text { I think that I am in the best organisation that provides the pre-hospital } \\
\text { care in the kingdom. } \\
\text { Urban paramedic } \\
\text { I also really like the work environment, as it is really comfortable and } \\
\text { my colleagues are really nice and we cooperate with each other }\end{array}$ \\
\hline Work stress & $\begin{array}{l}\text { Rural EMT } \\
\text { Well, I hate that we have physiological effects due to the cases we } \\
\text { see in the scenes and the administrative pressure. What I mean by } \\
\text { administrative pressure is that they don't give us the flexibility to } \\
\text { switch shifts. } \\
\text { Urban paramedic } \\
\text { I really hate that we have a lot of calls that are out of our coverage } \\
\text { area so sometimes we end up covering a big area and that } \\
\text { translates to a longer response time from us. }\end{array}$ \\
\hline Training and education & $\begin{array}{l}\text { Rural EMT } \\
\text { I think that we need a mandatory training for all of the EMS workers } \\
\text { so that it's going to be part of our annual evaluations. }\end{array}$ \\
\hline
\end{tabular}




\begin{tabular}{|c|c|}
\hline & $\begin{array}{l}\text { I think Red Crescent needs to promote the EMTs to be paramedics } \\
\text { based on their level of experience. Also, we need to get the } \\
\text { necessary support to advance our studies. } \\
\text { Rural EMT } \\
\text { We should also create a scholarship chance for the EMT to continue } \\
\text { their education in order to become paramedics. } \\
\text { Rural EMT } \\
\text { Sometimes our employees would not provide high standard care to } \\
\text { the patients because we need to have updated training and } \\
\text { courses which is sometimes difficult for us who are working in the rural } \\
\text { area because most of the courses are only available in the main } \\
\text { cities and we need to travel to access them. }\end{array}$ \\
\hline Skills base & $\begin{array}{l}\text { Rural manager } \\
\text { On the scope of practice, a paramedic can give a medication and } \\
\text { do an advanced intervention. EMT on the other hand cannot give } \\
\text { medication and an advance intervention. It would be better for } \\
\text { patients to receive the definitive care by a paramedic. }\end{array}$ \\
\hline Female EMS & $\begin{array}{l}\text { Urban manager } \\
\text { As Saudis, we have sexual separation concept in our culture. So } \\
\text { sometimes female patients request for female nurse or female } \\
\text { paramedic so they can get the treatment directly from them. } \\
\text { In my opinion, it would help if we have female paramedics for the } \\
\text { female patient cases. } \\
\text { Rural EMT } \\
\text { I think in terms of population, there are more female patients located } \\
\text { in the urban area unlike in the rural area. Personally, I have not } \\
\text { encountered female patients refusing transport in my area. } \\
\text { I am afraid that female paramedics won't provide the services like } \\
\text { the male paramedics. As I mentioned before, we rarely encounter } \\
\text { female patients refusing transport because we are male, in fact I } \\
\text { can't remember any instance. }\end{array}$ \\
\hline
\end{tabular}

\section{Patient Factors}

There were a number of patient factors that were identified as affecting EMS service outcomes. Again, the lack of female EMS staff across the region was identified as an issue, with some patients noted as refusing treatment due to the lack of female personnel. For rural EMS staff specifically, one of the key problems was geographic distance, with the location for providing assistance often a long way from the station. However, rural participants also identified an inability to sometimes even find the patient due to a lack of clear directions and signposting in rural areas. Both rural and urban participants noted some patients as having unrealistic expectations of how EMS operate, and this resulted in dissatisfaction for both EMS staff and the patient. An example of this issue was cited as pressure from patients to be taken to a specific hospital, rather than simply the closest suitable healthcare facility, which would result in longer transportation times and delays for subsequent callouts. Concerningly, some participants were worried about the potential for both physical and verbal abuse from patients. On a positive note, the EMS staff believed that these concerns could possibly be successfully addressed through widespread public awareness campaigns aimed at educating the general public about the role of EMS. 


\begin{tabular}{|c|c|}
\hline SUB-THEME & EXEMPLAR QUOTES \\
\hline Unrealistic patient expectations & $\begin{array}{l}\text { Urban Paramedic } \\
\text { Some patients refuse being transported to the nearest } \\
\text { hospital by the ambulance just because they want a } \\
\text { specific hospital which may be so far from their location. }\end{array}$ \\
\hline Patient awareness & $\begin{array}{l}\text { Rural EMT } \\
\text { I recommend increasing public awareness so that people } \\
\text { can only call us when they really need us. This is because } \\
\text { sometimes we receive a call just for checking the vital } \\
\text { signs and while attending to that, we end up leaving our } \\
\text { area uncovered. }\end{array}$ \\
\hline Demand for female EMS & $\begin{array}{l}\text { Rural EMT } \\
\text { I think the culture play role because I encountered some } \\
\text { cases when I used to work in the urban station. When we } \\
\text { reached the scene, the female patient refused to be } \\
\text { treated and transported by us. }\end{array}$ \\
\hline Location of patients & $\begin{array}{l}\text { Rural EMT } \\
\text { Of course, with the longer travel in the rural area we take } \\
\text { a longer time to reach our patients. Sometimes we face } \\
\text { difficulty locating the patient as we cover an area which } \\
\text { we are not fully familiar with, for example we may receive } \\
\text { a call from } 50 \text { kilometres away from our station. Also } \\
\text { sometimes we need to ask for backup from the fire- } \\
\text { fighters when we face difficulties reaching a location by } \\
\text { our regular ambulance car, for example a patient in an } \\
\text { area that needs a } 4 \text { by } 4^{1} \text { car. } \\
\text { *1. This refers to four-wheel drive vehicles. }\end{array}$ \\
\hline Patient / Family violence & $\begin{array}{l}\text { Rural EMT } \\
\text { I think it is because sometimes the callers are not the } \\
\text { patients themselves (relative), so when we arrive the } \\
\text { patients refuse to be transported. } \\
\text { I think we need more protection from the verbal and } \\
\text { physical violence. }\end{array}$ \\
\hline
\end{tabular}

\section{Organisational Factors}

It is not surprising that organisational factors were identified as critical in improving EMS services in both rural and urban areas. Participants commented positively about working for Saudi Red Crescent ingeneral and noted the supportive environment for staff. However, there were also a number of factors identified, many specific to rural areas, that were considered barriers to effective EMS. One participant observation was the fact that rural areas supported more patients as a result of trauma, compared to more medical conditions callouts occurring in urban areas, which supported quantitative findings from previous stages of the wider project [10-12]. 


\begin{tabular}{|c|c|}
\hline SUB-THEME & EXEMPLAR QUOTES \\
\hline Coordination with other services & $\begin{array}{l}\text { Rural EMT } \\
\text { We need more coordination with the Ministry of Health } \\
\text { ambulances because each hospital has their own } \\
\text { ambulances so when their chronic patients need to be } \\
\text { taken to their hospital they can transport him/her. }\end{array}$ \\
\hline Medical Versus Trauma Cases & $\begin{array}{l}\text { Rural EMT } \\
\text { Most of our cases in the rural area are trauma while the } \\
\text { urban cases are medical. }\end{array}$ \\
\hline Hub and spoke model & $\begin{array}{l}\text { Rural EMT } \\
\text { We need to establish a small trauma centre in every } 100 \\
\mathrm{~km}^{2} \text { area so that we do not have to travel for long with } \\
\text { the patients. Also, we need more ambulance stations } \\
\text { and flight medics. Therefore, more work needs to be } \\
\text { done by all the health organisations in the kingdom. }\end{array}$ \\
\hline Resources (human and physical) & $\begin{array}{l}\text { Rural EMT } \\
\text { I think the vehicles we have are not suitable for the rural } \\
\text { area. More so, they are outmoded and should therefore } \\
\text { be replaced with modern ones equipped with the } \\
\text { modern equipment which is suitable for a rural area. } \\
\text { Rural EMT } \\
\text { I think increasing the number of the ambulance crews } \\
\text { and stations for both rural and urban will help. Also, we } \\
\text { need to establish new stations for the packed areas. } \\
\text { Rural EMT } \\
\text { The EMS services in the rural area differ from those in } \\
\text { urban area. Urban area EMS services have more } \\
\text { resources, equipment and brand new cars compared } \\
\text { to the rural areas. Also, the types of trauma injuries are } \\
\text { usually more severe in rural areas compared to those in } \\
\text { urban areas. }\end{array}$ \\
\hline Location, local knowledge, access & $\begin{array}{l}\text { Rural EMT } \\
\text { The rural areas take longer duration time. Sometimes } \\
\text { we travel } 50 \mathrm{~km} \text { to reach the patients, then spend some } \\
\text { time at the scene and finally we have to travel back } 50 \\
\mathrm{~km} \text {. These combined take too much time. } \\
\text { Yes. Also the information given to the dispatcher affects } \\
\text { the response time. For example, sometimes the caller } \\
\text { could not give us the right location, so it would take us } \\
\text { too long to reach the scene. }\end{array}$ \\
\hline
\end{tabular}




\section{DISCUSSION}

The purpose of this study was to examine the lived experiences of EMS personnel in Saudi Arabia. Through this approach, it was possible to identify key issues that staff face in their day-to-day work practice and ascertain factors that may lead to service disparities between rural and urban areas. The thematic analysis of responses indicated that there were a number of differences that may explain the existing disparities in the provision of emergency medical services in rural and urban regions. Three key thematic areas were identified, and these were EMS personnel issues; patient factors; and organizational factors. However, it is worth noting that within each theme there were often a number of areas of similarity, and that urban areas regularly faced similar problems to rural locations. The following discussion section will focus on the key problem areas identified and suggest possible solutions that could be easily implemented, and which do not require substantial financial or infrastructure changes.

\section{Work Conditions}

The responses indicate that both urban and rural staff have an incomplete understanding of the overall EMS system across both areas, which led to potential confusion regarding issues outside of their direct daily involvement. However, they were generally very positive about working for Saudi Red Crescent. One of the emerging issues involved stressful work conditions linked to the handling and performing certain medical procedures. Workplace stress arising from patients' interactions and cultural conflicts had an impact on EMS staff, with it known that EMTs who experience verbal and physical assault may develop low self-esteem. [19] The cultural factors in service provision can bring challenges for a health care provider. [20] Addressing the problem requires EMS staff to undergo training on cultural competence skills to help in the realization of a holistic prehospital care. [20, 21]

One of the factors contributing to improvement of EMS professional efficiency involves the ability to have integrated coordination and effective decision making process. Such operating conditions is important in enhancing productivity of EMS teams in dispatch and patient evacuation. [22] However, the gender of staff was a major issue influencing patient perception of EMS performance. As noted by Alharthy et al, female patients show a preference to be attended to by female paramedics in critical care situations where the presence of male staff is often perceived to cause inconvenience. [23]

\section{Patient Factors}

Patient factors, such as unrealistic expectations, awareness levels regarding EMS services and aggressive behaviours, were identified as influencing the efficiency of the service. For example, paramedics would decide on the dispatching a patient to closest facility depending on the level of injury [24], but patients may express a wish for another option that was perceived to be superior. Patient behaviours, such verbal and physical violence and resistance due to cultural factors, made it difficult for the EMS paramedics to perform certain health procedures without respecting cultural or religious beliefs of the patients. [19] Navigating these factors could be a challenge, especially in sharing patient information, to ensure successful delivery of medical care. [25].

\section{The Organizational Factors and EMS service}

In recent years, Saudi Arabia has seen great advances in the provision of EMS. [26] Among the positive changes is the adoption of the Anglo-American model of EMS which facilitates rapid transport of patients to an emergency department by clinically competent paramedics, with Saudi Red Crescent providing a comprehensive EMS service throughout the country. [26] However, in spite of this expansion and investment, participants perceived that the lack of adequate human resources and medical equipment contributed to lower quality of EMS in the rural areas. Reduced access to advanced medical equipment in the rural areas made it difficult for EMS teams to handle conditions such as fractures, bleeding and cardiac arrest. In addition, some skills shortages in performing certain medical procedures and on-scene drug administration contributed to the limited inefficiency and poor quality EMS services.

Within rural areas, there is a challenge for EMS organizations to provide training incentives for EMTs to acquire hands-on skills on management and delivery of advance pre-hospital services [8]. Retaining of employees for EMS organizations is also a critical challenge for EMS organizations in rural areas, with some EMS teams found to be dependent on volunteers in attending to rural populations. [3] Further, EMS organizations in rural areas have cited difficulty in providing continuing education programs in rural areas to EMS and burn-out as a contributing factor to staff retention problem. [27] 
Having common operating standards across all locations would enhance quality and improve patient outcomes in rural areas [28], with their implementation essential for ensuring effective workflows and community delivery of EMS services. [29] EMS staff working in rural areas should be provided with local hands-on training that reflects the predominant types of injuries and conditions affecting rural regions and help to reduce disparities in care. [30]

The large area of coverage by rural EMS organizations is reflected in increased response times, which in turn have a negative impact on recovery time for patients. [3] The lack of a reliable functional communication network also makes it difficult to reach patients within the shortest time which poses risk to patients in critical conditions. [20] Few designated traumatic centres and the increased severity of trauma injuries in rural areas also complicated patient transportation and admission for immediate medical intervention. [31]

\section{CONCLUSIONS}

The quality and efficiency of EMS services, in both rural and urban areas, was affected by a number of over-arching organizational and patient factors, and the level of infrastructure. Implementing major policy shifts, such as recruitment of female EMS professionals, will be critical in addressing challenges resulting from cultural and patient attitudes, but it is acknowledged that this will take time. Quicker changes, such as improving the skills and advanced training options for rural EMS staff, may help to remediate some of the serious injuries and other types of trauma injuries evident in those areas. Public awareness campaigns may also be effective in addressing the identified misconceptions about the role of EMS in Saudi Arabia.

\section{References}

1. Chng C, Collins J, Eaddy S. A comparison of rural and urban emergencymedical system (EMS) personnel: a Texas study. Prehosp Disaster Med. 2001; 16 (3): 159165.

2. Chanta S, Mayorga M, McLay L. Improving emergency service in rural areas: a bi-objective covering location model for EMS systems. Ann Oper Res, 2014; 221 (1): 133-159.
3. King N, Pigman M, Huling S, Hanson B. EMS Services in Rural America: Challenges and Opportunities. [cited 27 September 2020]. Available from https://www.ruralhealthweb.org/NRHA/media/Emerg e NRHA/Advocacy/Policy\%20documents/05-11-18NRHA-Policy-EMS.pdf

4. Alanazy A, Wark S, Fraser J, Nagle A. Factors impacting patient outcomes associated with use of emergency medical services operating in urban versus rural areas: A systematic review. Int J Environ Res Public Health. 2019; 16(10): 1728.

5. Aftyka A, Rybojad B, Rudnicka-Drozak E. Are there any differences in medical emergency team interventions between rural and urban areas? A single-centre cohort study. Aust J Rural Health. 2014; 22(5): 223-228.

6. Moore M, Hamilton A, Cairns K, Marshall A, Glover B, Mccann $C$, et al. The Northern Ireland Public Access Defibrillation (NIPAD) study: effectiveness in urban and rural populations. Heart, 2008;94(12): 1614-1619.

7. Svensson L, Karlsson T, Nordlander R, Wahlin M, Zedigh $C$, Herlitz J. Safety and delay time in prehospital thrombolysis of acute myocardial infarction in urban and rural areas in Sweden. Am J Emerg Med. 2003; 21 (4): 263-270.

8. Mathiesen W, Bjørshol C, Kvaløy J, Søreide E. Effects of modifiable prehospital factors on survival after out-ofhospital cardiac arrest in rural versus urban areas. Crit Care. 2018:22(1): 1-9.

9. FatovichD, Phillips M, Langford S, Jacobs I. A comparison of metropolitan vs rural major trauma in Western Australia. Resuscitation. 201 1;82(7): 886-890.

10. Alanazy A, Wark S, Fraser J, Nagle A. Utilization of prehospital emergency medical services in Saudi Arabia: An urban versus rural comparison. J Emerg Med Trauma Acute Care, 2021;2020(2): 1-7.

11. Alanazy A, Wark S, Fraser J, Nagle A. A comparison of pre-hospital emergency medical services' response and duration times in urban versus rural areas of Saudi Arabia. Austral J Paramed, 2020;17:1-7.

12. Alanazy A, Wark S, Fraser J, Nagle A. Nontransported Cases after Emergency Medical Service Callout in the Rural and Urban Areas of the Riyadh Region. Saudi J Med Med Sci, 2021;9(1):38-44.

13. 13. Noblit G, Hare R. Meta-ethnography: Synthesizing qualitative studies. London: Sage; 1988. 
14. Polit D, Beck C. Nursing research:Principles and methods. Philadelphia: Lippincott Williams \& Wilkins; 2004.

15. LoBiondo-Wood G, Haber $\mathrm{H}$. Nursing research: Methods, critical appraisal and utilisation. Sydney: Mosby; 2004.

16. Silverman D. Interpreting qualitative data. London: Sage; 2015.

17. St John W. Focus Group Interviews. In V. Minichiello, S. Sullivan, K. Greenwood, \& R. Axford (Eds.), Handbook of Research Methods for Nursing and Health Sciences 2nd Edition (pp. 447-461). Frenchs Forest, Australia: Pearson; 2004.

18. Braun $\vee$, Clarke $\vee$. Using thematic analysis in psychology. Qual Res in Psych. 2006; 3(2): 77-101.

19. Wang $P$, Fang $P$, Wu C, Hsu H, Lin C. Workplace violence in Asian emergency medical services: a pilot study. Int J Environ Res Public Health. 2019; $16(20)$ : 3936.

20. Swihart D, Martin R. Cultural religious competence in clinical practice. [cited 5 October 2020]. Available from https://www.ncbi.nlm.nih.gov/books/NBK493216/

21. Attum B, Waheed A, Shamoon Z. Cultural competence in the care of Muslim patients and their families. [cited 5 October 2020]. Availabile from https://www.ncbi.nlm.nih.gov/books/NBK499933/

22. Chen W, Decker K. The Analysis of Coordination in an Information System Application - Emergency Medical Services. In: Bresciani P, Giorgini P, Henderson-Sellers B, Low G, Winikoff M. (eds). Agent-Oriented Information Systems II. AOIS 2004. Lecture Notes in Computer Science, vol 3508. Berlin: Springer; 2055.

23. Alharthy N, Alswaes S, Almaziad A, Alenazi N, Abdallah M, Alshehry M. Public perception of female paramedics at King Abdulaziz Medical City, Saudi Arabia. Int J Environ Res Public Health. 2018; 11 (1): 57.

24. Newgard, C, Mann N, Hsia R, Bulger E, Ma J, Staudenmayer $\mathrm{K}$, et al., Patient choice in the selection of hospitals by 9-1-1 emergency medical services providers in trauma systems. Acad Emerg Med. 2013; 20(9): $911-919$.

25. Ogilvie W, Moy H, GoldsteinS. EMS, Legal and Ethical Issues. [Accessed 10 October 2020]. Available from https://www.ncbi.nlm.nih.gov/books/NBK519553/.
26. Al Mutairi M, Jawadi A, Al Harthy N, Al Enezi, F, Al Jerian N, Qahtani A, et al., Emergencymedical service system in the Kingdom of Saudi Arabia. J Med Clin Res, 2016; 4(10): 13084-13092.

27. Freeman V, Slifkin R, Patterson P. Recruitment and retention in rural and urban EMS: results from a national survey of local EMS directors. J Public Health Manag Pract. 2009; 15(3): 246-252.

28. Reddy M, Paul S, Abraham J, McNeese M, DeFlitch C, Yen J. Challenges to effective crisis management: using information and communication technologies to coordinate emergency medical services and emergency department teams. Int J Med Inform. 2009; 78(4): 259-269.

29. Committee on Guidance for Establishing Crisis Standards of Care for Use in Disaster Situations; Institute of Medicine. Crisis Standards of Care: A Systems Framework for Catastrophic Disaster Response. Washington (DC): National Academies Press (US); 2012

30. Pandit T, Ray R, Sabesan S. Managing medical emergencies in rural Australia: A systematic review of the training needs. Emerg Med Austral. 2019;31 (1): 2028.

31. Jarman M, Castillo R, Carlini A, Kodadek L, Haider A. Rural risk: geographic disparities in trauma mortality. Surgery. 2016;160(6): 1551-1559. 